\title{
Quantitative assessment of in planta distribution of metabolic activity and gene expression of an endophytic fungus
}

\author{
Scott Herd, ${ }^{1}$ Michael J. Christensen, ${ }^{2}$ Karyn Saunders, ${ }^{1}$ D. Barry Scott ${ }^{1}$ \\ and Jan Schmid'
}

1 Department of Microbiology and Genetics, Massey University, Palmerston North, New Zealand

2 AgResearch Grasslands, Palmerston North, New Zealand
Author for correspondence: Jan Schmid. Tel: +646 3504018. Fax: +6463505637. e-mail: J.Schmid@massey.ac.nz

\begin{abstract}
Using perennial ryegrass infected with an Acremonium transformant carrying the Escherichia coli $\beta$-D-glucuronidase gene (gusA) (GUS system) under control of a constitutive promoter, we have developed methods for the quantitative extraction of endophyte-associated GUS activity from plant material. Fluorometric assays of these extracts allow quantitative assessment of the distribution of endophyte-associated GUS activity within single plants (tillers) with high resolution. Fluorescence microscopy with the dye Imagene Green can in addition visualize individual GUS-expressing hyphae. Since the transformant expresses the GUS gene constitutively, GUS activity can be used as an indicator of in planta endophyte metabolic activity. Using this approach we found that (i) the concentration of endophyte metabolic activity in plant tissue decreases with increasing plant size, (ii) approximately $70 \%$ of endophyte metabolic activity present in a plant is located in the leaf sheaths, (iii) basal-apical gradients and lateral (younger to older tissue) gradients of endophyte metabolic activity exist and (iv) basal-apical gradients are established early in leaf development. Our data suggest that the concentration of endophyte in each part of the plant is regulated so that a predetermined threshold of total endophyte activity per plant is not exceeded and a consistent distribution pattern is maintained.
\end{abstract}

Keywords: endophytic fungi of ryegrass, reporter genes, in planta metabolic activity, in planta gene expression, Acremonium

\section{INTRODUCTION}

Unravelling the interactions between plant and fungus in endophytic mutualism at the cellular and molecular level is a challenging experimental task: the very processes one wants to study only take place during the association of the participating organisms which cannot easily be separated for analysis or manipulation. As a result of these difficulties, our knowledge of interactions between grass endophytes and their hosts is largely restricted to their final consequences. We know that the systemic presence of the endophyte in the intercellular spaces of the host elicits the synthesis of agriculturally important herbivore deterrents, increases drought re-

Abbreviations: ANOVA, analysis of variance; GUS, $\beta$-D-glucuronidase; MUG, 4-methylumbelliferyl glucuronide; MU, methylumbelliferone. sistance and leads to changes of grass morphology, growth rate and growth yield (Scott \& Schardl, 1993; Siegel \& Schardl, 1991; West, 1994). In contrast, our understanding of the interactions leading to these effects is very limited and mainly based on indirect evidence such as observations of the fungus in vitro or extrapolation from other systems (Porter, 1994; Siegel \& Schardl, 1991; West, 1994).

Advances in molecular biology have recently opened up new possibilities for studying plant-fungus interactions at the level of gene expression, using the GUS reporter gene system (Escherichia coli $\beta$-D-glucuronidase gene) (Jefferson, 1987). A number of groups have developed methods for transforming plant-associated fungi with this reporter gene under the control of a fungal promoter and demonstrated that fungal reporter gene expression can easily be observed in planta due to lack of GUS activity in the host plant tissue (Bunkers, 1991; 
Couteaudier et al., 1993; Mönke \& Schäfer, 1993; Murray et al., 1992; Smit \& Tudzynski, 1992). For Acremonium grass endophytes, methods for transformation with the GUS reporter gene and for reintroducing these transformants into plants have been developed by Murray et al. (1992) and Latch \& Christensen (1985).

These studies have established that the GUS reporter gene could in principle be used to monitor spatial and temporal patterns of in planta endophyte gene expression, which would allow the definition of functions of genes involved in the symbiosis. Because of the ease and sensitivity of fluorochrome-based GUS assays (Jefferson, 1987) their use could also provide an attractive alternative method for determining the distribution of endophyte mycelium within the plant if the GUS gene is constitutively expressed by the endophyte; all other current methods for determining fungal biomass in planta, such as microscopic observation, chemical, immunological or PCR-based assays of fungal compounds have drawbacks in terms of sensitivity, time requirements or cost (Ball et al., 1995; Ride \& Drysdale, 1972; Roberts et al., 1988; Takenaka, 1995).

However, reliable information can only be gained from such uses of reporter genes if methods are developed which ensure that fungal reporter enzyme activity is extracted from plant material with consistent high efficiency. Otherwise loss of sensitivity, day-to-day variation or tissue-specific differences in extraction efficiency will obscure the information which the use of GUS-containing endophytes could provide. None of the previous studies on the use of GUS in plant-associated fungi have included the development and/or testing of appropriate extraction methods.

Using an Acremonium transformant, expressing the GUS gene under the control of a constitutive heterologous promoter, the Aspergillus nidulans gpdA (glyceraldehyde-3-phosphate dehydrogenase gene) promoter (Devchand \& Gwynne, 1991; Murray et al., 1992; Roberts et al., 1989), we have therefore developed methods which meet the above criteria and allow sensitive and reliable quantification of in planta GUS expression by endophytic fungi. In a first application we have used these methods for exploring the spatial distribution of Acremonium endophyte metabolic activity within perennial ryegrass plants.

\section{METHODS}

Strains and plant growth conditions. All experiments were carried out with Acremonium transformant FM13 (Murray et al., 1992) or its parent strain Lp1 in perennial ryegrass (variety 'Grasslands Nui'). FM13 was created by Murray et al. (1992) through cotransformation of Lp1 with the hygromycinresistance plasmid pAN7-1 (Punt et al., 1987) and the plasmid pNOM-102 (Roberts et al., 1989), containing the GUS reporter gene under the control of the Aspergillus nidulans glyceraldehyde-3-phosphate dehydrogenase promoter. Its GUS activity is in the middle range of activities observed for GUS-expressing Lp1 transformants (Murray et al., 1992). Ryegrass seedlings were infected with the endophytes one year prior to their use in this study, using the method of Latch \& Christensen (1985), and tufts of plants were maintained in greenhouses in 1.41 pots containing potting mix to which Osmocote (Grace Sierra, Australia) slow-release fertilizer had been added. Plants were not cut back within two months preceding their analysis for GUS activity. To control powdery mildew, leaves were rubbed weekly with cotton swabs containing $70 \%$ ethanol.

Determination of efficiency of extraction of endophyte GUS activity from plant material. Multiple plants were removed from tufts of grass and dissected into samples containing (i) leaf blades, (ii) leaf sheaths, (iii) emerging leaves, (iv) all immature tissues in the core of the stem and (v) roots. The tissues were then cut into $1-2 \mathrm{~mm}^{2}$ pieces. This material, (30-120 mg, equivalent to 5-20 mg dry weight) was used for extraction and transferred into preweighed Eppendorf tubes whose lids had been perforated using a needle. Each Eppendorf tube was immediately transferred to $-20^{\circ} \mathrm{C}$. When dissection of a plant was complete, all tubes were transferred to the cavities of a metal block from a dry bath (Thermolyne) precooled to $-70^{\circ} \mathrm{C}$ and insulated by a styrofoam shell. Liquid nitrogen was then added to each sample and it was ground to a fine powder using a micropestle (Eppendorf 0030120973). Powdered samples were transferred to precooled $\left(-20^{\circ} \mathrm{C}\right)$ vacuum flasks and freeze-dried for $24-48 \mathrm{~h}$. Immediately after removal from the freeze-drying apparatus, samples were weighed and then immediately suspended in $600 \mu \mathrm{l}$ GUS extraction buffer $[50 \mathrm{mM}$ sodium phosphate, $10 \mathrm{mM} \beta$-mercaptoethanol, $10 \mathrm{mM}$ sodium-EDTA, $0 \cdot 1 \%$ sodium lauryl sarcosine, $0.1 \%$ Triton X-100; Jefferson (1987)], precooled to $4{ }^{\circ} \mathrm{C}$, and placed on ice. Samples were then placed in an ethanol-ice bath and sonicated using an MSE Soniprep 100 sonicator with a microtip. Samples were subjected to 15 cycles of sonication at an amplitude of $14 \mu \mathrm{m}$ for $15 \mathrm{~s}$ and $40 \mu \mathrm{l}$ samples were removed prior to sonication and after $1,2,3,4,7,11$ and 15 cycles; $40 \mu \mathrm{l}$ of buffer was added following each sampling. Samples were subsequently centrifuged for $5 \mathrm{~min}$ at $15000 \mathrm{~g}$ and supernatant was collected and kept on ice until used in GUS assays.

GUS activity was analysed by a modification of the methods described by Jefferson (1987). To 10-160 $\mu$ l of supernatant, 4methylumbelliferyl glucuronide (MUG) in GUS extraction buffer was added to give a concentration of $1 \mathrm{mM}$ MUG in a final volume of $200 \mu \mathrm{l}$, and the mixture was incubated at $37^{\circ} \mathrm{C}$ (both extract and MUG stock solution were brought to this temperature before mixing). Throughout all assays the concentration of MUG remained above $0.9 \mathrm{mM}$. Samples of $40 \mu \mathrm{l}$ were taken at four timepoints $10-300 \mathrm{~min}$ after the assay had been started and were mixed with $2 \mathrm{ml}$ stop buffer $\left(0 \cdot 2 \mathrm{M} \mathrm{Na}_{2} \mathrm{CO}_{3}\right)$. A Hoefer TK 100 fluorometer (excitation $355 \mathrm{~nm}$, emission $460 \mathrm{~nm})$, calibrated with $50 \mathrm{nM}$ methylumbelliferone $(\mathrm{MU})$ was used to determine $\mathrm{MU}$ concentration at each time point. Samples were diluted with stop buffer if their fluorescence exceeded the linear reading range of the fluorometer. Linear regression was used to calculate enzyme activities. Assays were always conducted within 60-90 min after extraction since overnight storage of extracts at $-20^{\circ} \mathrm{C}$ or $-70^{\circ} \mathrm{C}$ led to significant reductions in activity.

GUS activity in the supernatant samples removed after different numbers of sonication cycles was subsequently plotted against the inverse of the number of sonication cycles to determine the maximum extractable activity (the activity extractable by an infinite number of sonications). Based on the latter value the fraction of the maximum extractable activity released by different numbers of sonication cycles or by 


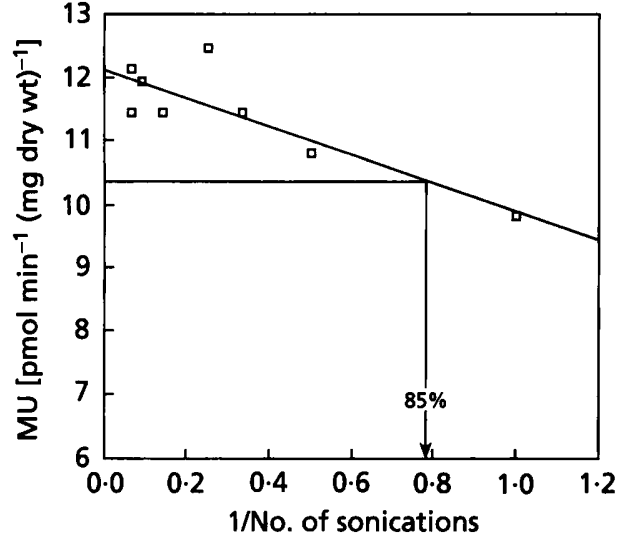

Fig. 1. Example of determination of maximum activity in plant tissue and the percentage released by sonication. Ground plant tissue (in this case immature tissue from the core of the stem) was suspended in extraction buffer, sonicated, and GUS activity in the supernatant was determined as described in Methods. Maximum activity was estimated, using linear regression, as the activity at $1 / \mathrm{no}$. of sonications $=0$, in this case $12.119 \mathrm{pmol}$ MU min $^{-1}$ (mg plant tissue) ${ }^{-1}$. This value was then used to define the number of sonications required to release at least $85 \%$ of this activity (labelled in Figure), in this case two cycles of sonication.

grinding alone was determined as well as the number of sonication cycles required to release at least $85 \%$ of all activity (see Fig. 1 for an example).

Analysis of the distribution of endophyte GUS activity within individual plants. Plants were harvested between November 1995 and January 1996. Dissection of individual plants (or to use the agronomic term, tillers) was carried out as follows. Each mature leaf of each plant was dissected into upper and lower half of the leaf blade and upper and lower half of the leaf sheath. The emerging leaf of each plant was dissected into three portions, the uppermost section protruding from the stem plus the upper and lower half of the part of the emerging leaf obscured by the surrounding leaf sheaths of the mature leaves. Additional sections included immature prospective leaf tissues within the core of the stem and new shoots (axillary shoots) emerging between the leaf sheaths and roots (Fig. 2). Sections whose fresh weight exceeded $120 \mathrm{mg}$ were divided between two Eppendorf tubes, one of which was used for dry weight determination only. The extraction and assay of GUS activity was carried out as described above, using four cycles of sonication.

Fluorescence photomicroscopy. Fluorescence microscopy employed the fluorogenic GUS substrate Imagene Green (5dodecanoylaminofluorescein di- $\beta$-D-glucuronide; Molecular Probes). This is a lipophilic analogue of fluorescein $\beta$-Dglucuronide which can diffuse across membranes; the fluorescent cleavage product [5-(N-dodecanoyl)aminofluorescein] is retained by the cell (Haughland, 1992). Plant sections were incubated with $50 \mu \mathrm{M}$ Imagene Green in extraction buffer without mercaptoethanol at room temperature for $1-5 \mathrm{~h}$. Samples were analysed with a Nikon Diaphot inverted microscope using an Omega XF22 filter set (excitation $485 \mathrm{~nm}$, dichroic mirror cut-off $505 \mathrm{~nm}$, emission $530 \mathrm{~nm}$ ). For photography a Nikon F-601 camera with Fuji Neopan 400 film was used.

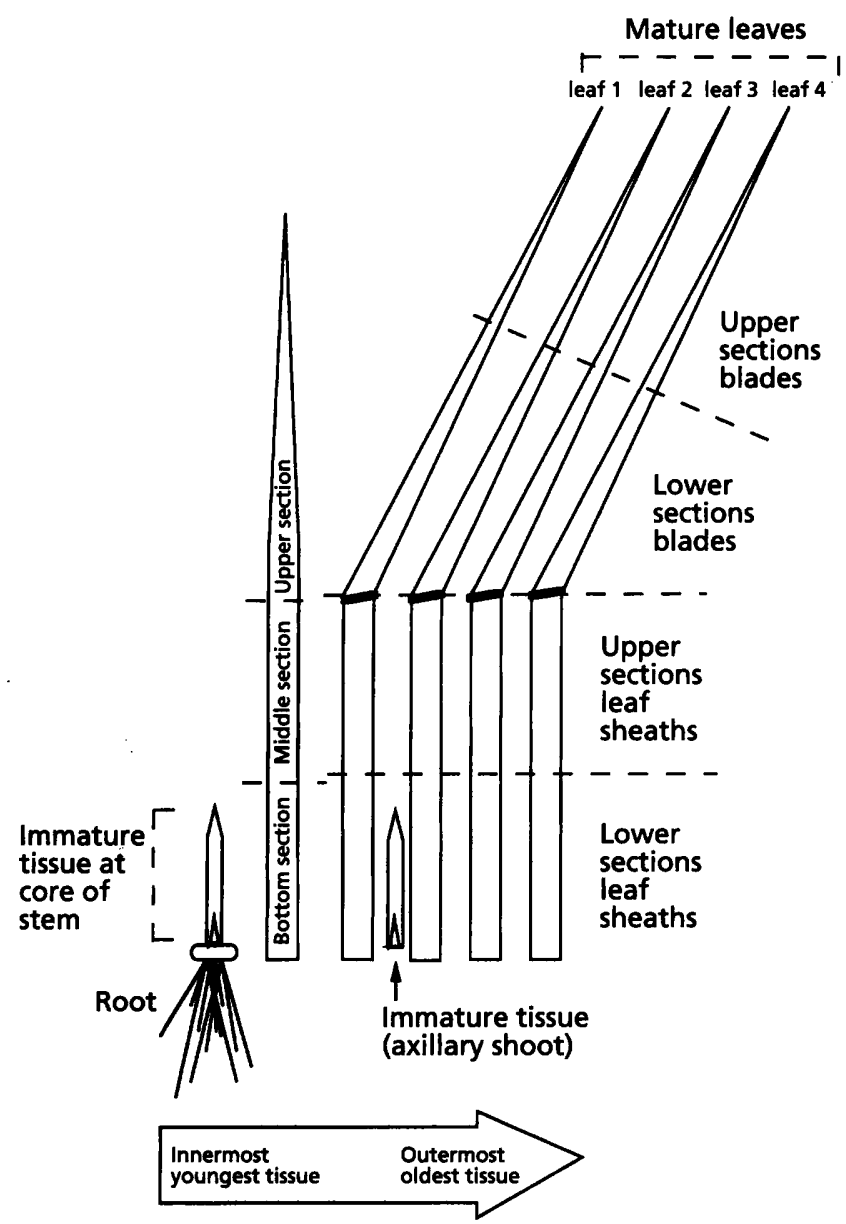

Fig. 2. Exploded view of a grass plant showing sections obtained for analysis of the distribution of endophyte metabolic activity. The plant shown has four mature leaves, in which blades are separated from sheaths by the ridge of the ligule (shown as a thick dividing line). Some of the plants analysed only had two mature leaves, lacking leaves 3 and 4 shown in the Figure. Sections subdividing plant structure are marked by dashed lines.

\section{RESULTS}

\section{Development of methods for extraction of endophyte-associated GUS activity from plant tissue}

We initially attempted to release endophyte-associated GUS activity from plant material solely by grinding samples in liquid nitrogen. However, microscopic observation of the resulting preparations after their suspension in extraction buffer revealed the presence of fragments of up to $100 \mu \mathrm{m}$ diameter, in which GUS activity was retained within hyphae as assessed by staining with the fluorogenic GUS substrate Imagene Green (data not shown).

We therefore chose sonication to further break up such fragments and thus release a larger proportion of GUS activity. To assess the effect of sonication we compared the percentage of all extractable activity released by grinding alone and various numbers of sonication cycles 
Table 1. Effect of sonication on GUS activity extraction

\begin{tabular}{|c|c|c|c|c|}
\hline Tissue & $\begin{array}{l}\text { Fraction of } \\
\text { total activity } \\
\text { released by } \\
\text { grinding only } \\
(\text { mean } \pm \mathrm{SD})^{*} \|\end{array}$ & $\begin{array}{c}\text { Fraction of } \\
\text { total activity } \\
\text { released after } \\
15 \text { sonication } \\
\text { cycles } \\
\text { (mean } \pm S D) \dagger \|\end{array}$ & $\begin{array}{l}\text { No. of } \\
\text { sonication } \\
\text { cycles } \\
\text { required to } \\
\text { release } \\
\geqslant 85 \% \text { of } \\
\text { total activity } \ddagger \|\end{array}$ & $\begin{array}{c}\text { Fraction of } \\
\text { total activity } \\
\text { released after } \\
4 \text { sonication } \\
\text { cycles } \\
\text { (mean } \pm \mathrm{SD}) \lessgtr \|\end{array}$ \\
\hline Leaf blade & $0.81 \pm 0.09$ & $1.01 \pm 0.05$ & $<1-2$ & $0.93 \pm 0.06$ \\
\hline Leaf sheath & $0.70 \pm 0.12$ & $1 \cdot 01 \pm 0 \cdot 21$ & $<1-3$ & $0.85 \pm 0.15$ \\
\hline Emerging leafg & $0.85 \pm 0.18$ & $1 \cdot 03 \pm 0 \cdot 24$ & $<1-4$ & $0.89 \pm 0.12$ \\
\hline Immature leaf tissue ${ }^{* *}$ & $0.72 \pm 0.18$ & $1.06 \pm 0.08$ & $<1-4$ & $0.85 \pm 0.15$ \\
\hline Root & $0.52 \pm 0.16$ & $1 \cdot 15 \pm 0.48$ & $2-4$ & $0.80 \pm 0.09$ \\
\hline
\end{tabular}

* Activity per mg plant tissue in supernatant prior to sonication as percentage of total extractable activity calculated as described in Fig. 1.

tObtained by comparing the activity in a supernatant sample collected after 15 cycles of sonication with the total extractable activity calculated as described in Fig. 1.

$\ddagger$ Determined using linear regression as described in Fig. 1 .

$\$$ Obtained by comparing the activity in a supernatant sample collected after the fourth cycle of sonication with the total extractable activity calculated as described in Fig. 1.

\| Eight independent extractions were carried out for immature leaf tissue, three for leaf sheaths and four extractions for each of the remaining tissue types.

I Emerging leaf sections contained the youngest leaf whose tip had emerged from the stem and was visible without dissecting the plant but which had not yet acquired a fully differentiated ligule, the ridge marking the border between leaf sheath and leaf blade.

** Immature leaf tissue samples contained the undifferentiated tissue at the core of the stem (apical meristem) plus partially differentiated leaves within the core of the stem which were not visible without dissecting the plant.

as described in Methods. The results of these experiments for various tissue types are shown in Table 1. Grinding alone released only an estimated $0.52-0.85$ of the total GUS activity; furthermore extraction efficiency differed between tissue types. Extraction from roots was $40 \%$ less efficient than that from the remaining cell types; differences between the latter ranged from 3 to $21 \%$. Sonication for 15 cycles (the maximum number tried) could in contrast release virtually all activity and differences in extraction efficiency between different tissue types did not exceed $13 \%$. In order to keep differences in extraction efficiency between different tissues at an acceptable level, while minimizing the time requirement of the method, we determined the minimum number of sonications required to release $\geqslant 85 \%$ of activity from all tissues. Four cycles of sonication sufficed, and differences in extraction efficiency between most tissue types ranged between 0 and $9 \%$ (Table 1 ). Extraction efficiency for root tissue was up to $16 \%$ lower than that of some of the other tissue types; however this was considered acceptable given the limited accuracy of GUS determinations in root tissue due to other factors (see below).

In order to relate GUS activity to the dry weight of the plant section analysed, it was necessary to freeze-dry and weigh plant samples prior to extraction of GUS activity. We confirmed that lyophilization did not reduce activity by conducting the extraction efficiency experiments described above with both fresh and lyophilized tissue and calculating the ratio between activity in lyophilized material and activity in fresh material. There were no significant tissue-specific differences in regard to the ratio of activity of lyophilized tissue: activity of fresh tissue $(1.25 \pm 0.26$ for leaf blade tissue, $1.16 \pm 0.68$ for leaf sheaths, $1.23 \pm 0.12$ for emerging leaf, $0.89 \pm 0.35$ for immature tissue at the core of the stem and 0.93 \pm 0.27 for root) and the combined ratio for all tissue types was $1 \cdot 092 \pm 0 \cdot 17$.

We therefore adopted, as our standard method, extraction of ground lyophilized material by four cycles of sonication. To verify the reproducibility of the method, we conducted three extractions and three GUS assays on the same root material and five extractions and ten assays on the same leaf blade material. Of the thirteen values of activity per dry weight obtained, twelve were within $10 \%$ of the sample averages and only one exceeded this limit ( $83 \%$ of sample average).

We also assessed background GUS activities obtained using this method in plants infected with untransformed endophyte (Table 2). These background activities were negligible compared to values obtained for samples from plants containing transformed endophytes except in the case of root tissue (see below). 
Table 2. Background GUS activity in extracts of ryegrass Nui infected with untransformed endophyte Lp1

\begin{tabular}{|c|c|}
\hline Tissue & $\begin{array}{l}\text { MU }\left[\mathrm{pmol} \mathrm{min} \mathrm{min}^{-1}\right. \\
\left.(\mathrm{mg} \text { dry wt })^{-1}\right]^{*}\end{array}$ \\
\hline Leaf blade $†$ & $0 \cdot 17 \pm 0.08(n=10)$ \\
\hline Wilted leaf blade & $0.27 \pm 0.24(n=2)$ \\
\hline Leaf sheath & $0 \cdot 22 \pm 0 \cdot 31\langle n=10\rangle$ \\
\hline Upper core of stem $\ddagger$ & $0 \cdot 24 \pm 0 \cdot 21(n=10)$ \\
\hline Lower core of stem $\neq$ & $0 \cdot 17 \pm 0 \cdot 11(n=10)$ \\
\hline Root & $1 \cdot 88 \pm 2 \cdot 06(n=10)$ \\
\hline
\end{tabular}

*Plant material was harvested from different tufts of grass on three different dates. Samples were processed according to the standard extraction method (see Methods).

†Includes blade tissue from emerging leaves.

$\ddagger$ Tissue from those parts of the core of the stem engulfed by the sheaths of the fully developed leaves. The lower core sections contained material from the basal $2 \mathrm{~cm}$ of the core, the upper sections the remainder of the core.

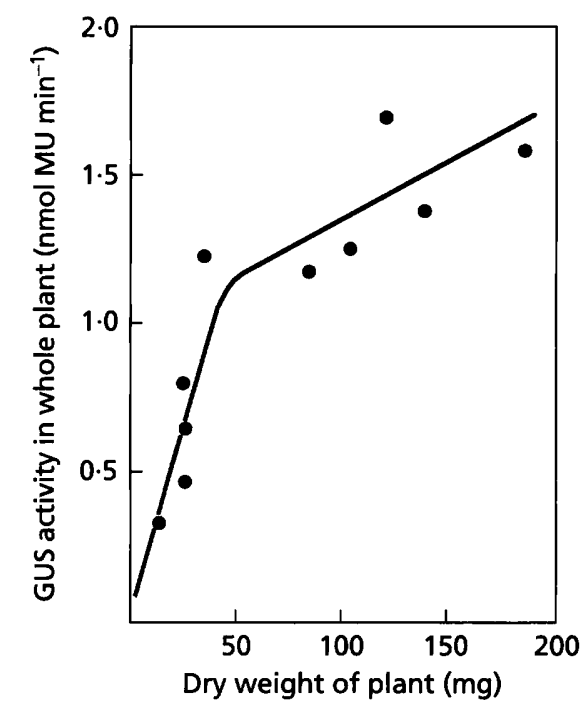

Fig. 3. Dependence of endophyte metabolic activity on plant size. Ten plants were dissected and GUS activity was assessed as described in Methods. In the graph the sum of GUS activities in all sections of each plant was plotted against the sum of dry weights of all sections. Since each plant was dissected completely, the latter sum represents the dry weight of the entire plant.

\section{Quantification of in planta endophyte metabolic activity as constitutive GUS expression}

In the endophyte transformant used in this study, GUS expression is driven by a constitutive heterologous promoter (Devchand \& Gwynne, 1991; Murray et al., 1992; Roberts et al., 1989). Levels of GUS activity should therefore be largely determined by overall protein synthesis rates of the endophyte, and GUS activity can thus serve as an indicator of metabolic activity of the endophyte. In a first application of the methods developed we therefore used GUS expression to assess in planta endophyte metabolic activity. To this end we dissected ten plants as described in Methods and assessed endophyte-associated GUS activity separately in each section of each plant. Five plants contained two mature leaves plus an emerging leaf in which the ligule (the ridge marking the border between sheath and blade) was not yet fully developed. Five plants contained four mature leaves plus an emerging leaf.

By pooling weights and activity data of all sections of each plant, we initially determined the relationship between total endophyte activity and plant weight (Fig. 3). Up to a plant dry weight of approximately $50 \mathrm{mg}$, endophyte metabolic activity doubled with every doubling in plant weight. Further doubling in plant weight, however, was only accompanied by a $1 \cdot 3$-fold increase in endophyte metabolic activity.

\section{Spatial gradients of in planta endophyte metabolic activity within plants}

Fig. 4 gives an overview of the endophyte metabolic activity per dry weight of tissue occurring in all sections obtained from the ten plants. The percentage of all endophyte metabolic activity present in different tissue types of each plant is shown in Fig. 5.

The highest concentration of endophyte metabolic activity occurred in the leaf sheaths, followed by that of mature leaf blades which had ten times less activity. The lower part of the emerging leaf had concentrations approximately ten times lower than that in mature leaf sheaths, and the upper part of the emerging leaf had a 100 -fold lower concentration of endophyte metabolic activity than mature leaf sheaths. Roots contained $\leqslant 0.3 \%$ of the concentration found in leaf sheaths (Fig. 4). The average activity per dry weight of root tissue was not significantly higher than the average background values found in plants containing untransformed endophyte (Table 2), indicating that little or no endophyte mycelium was present in the roots. Of all activity present in a plant, $65-85 \%$ was contained in the mature leaf sheaths, $10-30 \%$ in the mature leaf blades, $0-20 \%$ in immature tissue in the core of the stem and $0.5-10 \%$ in emerging leaf tissue (Fig. 5). The differences in percentage of total activity between the different tissue types were statistically significant with the exception of the difference between immature tissue and emerging leaf tissue (analysis of variance, ANOVA; $P<0.05$ ).

In the vast majority of leaves, the concentration of endophyte metabolic activity followed a basal-apical gradient (lower part of leaf sheath $>$ upper part of leaf sheath $>$ lower part of blade > upper part of blade); an ANOVA demonstrated the statistical significance of the observed gradient $(P<0.05)$. Basal-apical gradients also occurred in the emerging leaf tissues with concentration of activity being significantly higher in 


\begin{tabular}{lcccccccccc}
$\begin{array}{l}\text { Plant } \ldots . . \\
\text { Weight }\end{array}$ & 1 & 2 & 3 & 4 & 5 & 6 & 7 & 8 & 9 & 10 \\
(mg)... & 14 & 25 & 26 & 27 & 35 & 84 & 104 & 121 & 138 & 186 \\
\hline
\end{tabular}
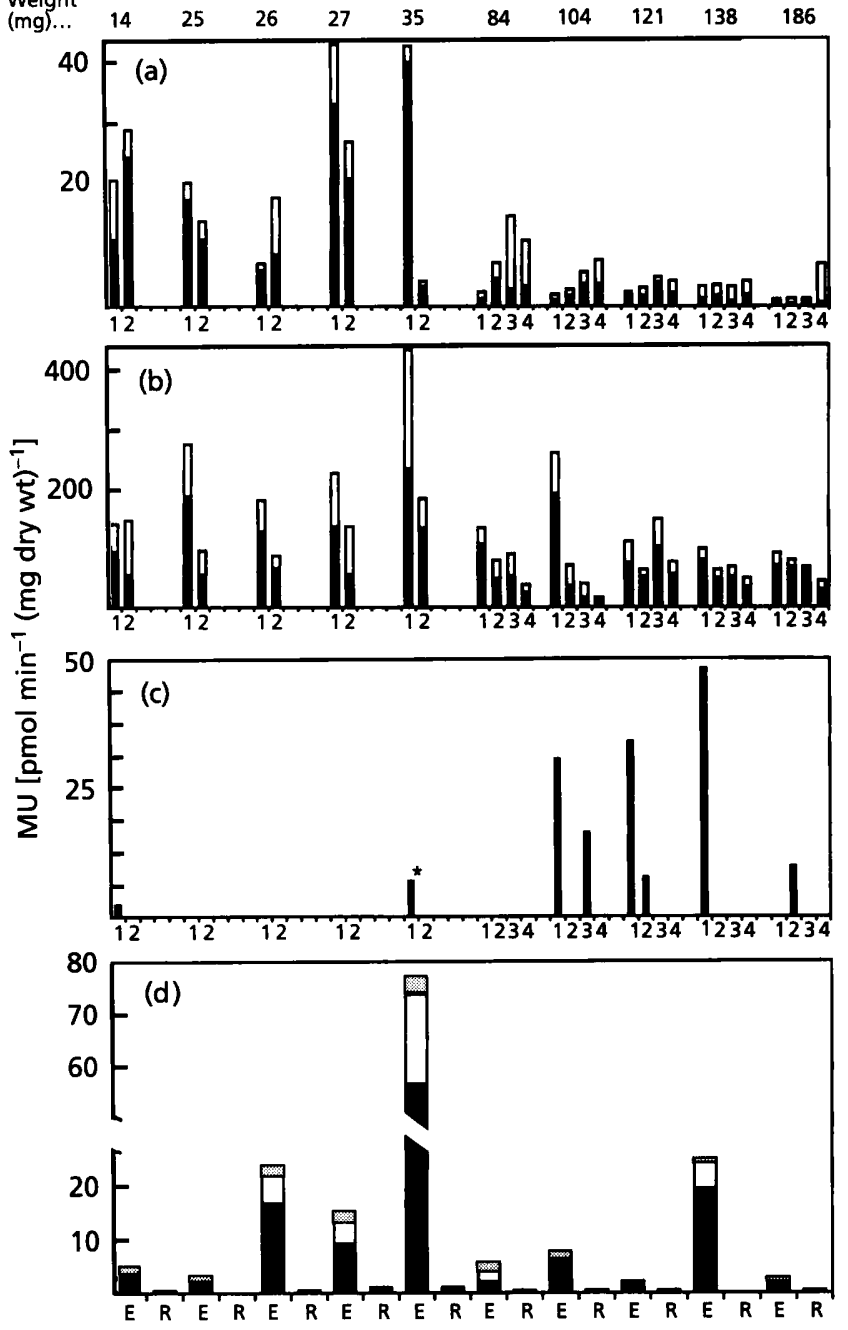

Fig. 4. Concentration of endophyte metabolic activity in different tissues of ten plants. Plants were grouped in the order of ascending weight and the dry weight of each plant is included at the top of the figure. Plants were dissected as described in Fig. 2. $(a, b)$ The open portions of the bars represent activity in the upper halves of the leaves (a) or leaf sheaths (b), filled portions of the bars show the activity in the lower halves. Mature blades and leaf sheaths are numbered, with 1 being the youngest leaf. (c) Immature tissues; numbers indicate the position of new (axillary) shoots in respect to the mature leaves. The bar labelled with an asterisk represents a newly emerging immature leaf in the core of the stem of plant 5. (d) Activity per $\mathrm{mg}$ of emerging leaf (E) with shaded areas at the top of each bar representing tissue above the ligule of the surrounding mature leaves, and open and filled parts of the bar representing upper and lower halves of the part of the emerging leaf surrounded by the leaf sheaths of the mature leaves; the activity per dry weight in roots $(R)$ is also shown.

bottom sections than in either middle or upper sections (ANOVA; $P<0 \cdot 05$ ). Pronounced exceptions to this rule were only observed in leaf blades 3 and 4 of plant 6 and leaf blade 4 of plant 10 , in which the concentration of activity in the upper part of the blade was several times higher than that in the lower part of the blade. Unlike

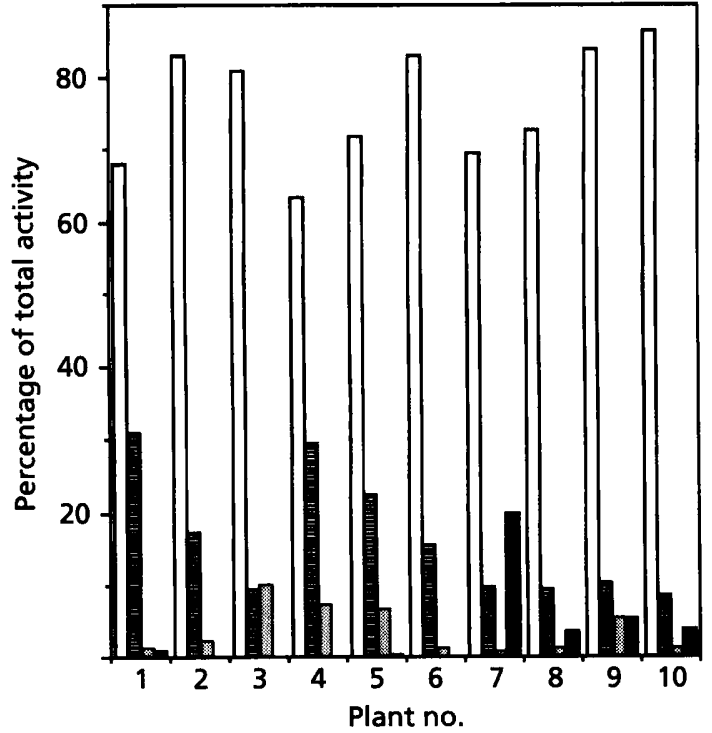

Fig. 5. Distribution of endophyte metabolic activity in different tissues of ten plants. The percentage of total activity located in the mature leaf sheaths ( $\square$ ), mature leaf blades (目), emerging leaves ( $(0)$ and immature tissues in the core of the stem ( $)$ of each plant is shown. Plant numbers correspond to those in Fig. 4.

any other material assayed, these three upper blade sections consisted of tissue which was severely wilted as a result of having been accidentally trapped underneath the containers in which the plants were raised. The apparent increase in activity was not due to a high background activity in wilted tissue (see Table 2); deterioration of plant tissue may thus increase endophyte metabolic activity.

Lateral gradients across the different mature leaf sheaths (but not across the mature leaf blades) were also observable. In eight out of ten plants, the innermost and youngest mature leaf sheath (no. 1) contained a higher concentration of endophyte metabolic activity than the remaining leaf sheaths. A paired $t$ test showed that in the average plant the concentration of activity in the no. 1 leaf sheath was significantly higher than the average of the concentration of activity within the remaining leaf sheaths of the same plant $(P<0.005)$. In young plants, the lateral activity concentration gradients seemed more pronounced than in the older plants but the statistical significance of these differences could not be shown.

Also apparent from Fig. 4 is a decline in the concentration of activity in the youngest leaf sheaths and leaf blades with plant size. Leaf blades nos 1 and 2 had an 8-fold higher concentration of endophyte metabolic activity in two-leaved plants than in four-leaved plants. In a $t$ test this difference was significant with $P<0.001$. Similarly, leaf sheaths nos 1 and 2 had a significantly (1.8-fold) higher concentration of activity in two-leaved plants than in four-leaved plants $(P<0.01 ; t$-test $)$. 


\section{Application of fluorescence microscopy for more precise spatial definition of the distribution of endophyte metabolic activity}

Future use of the GUS reporter gene in endophytes may include observations of genes which may be expressed only in very specific regions. We therefore explored the usefulness of the fluorogenic GUS substrate Imagene Green to visualize GUS-expressing hyphae using fluorescence microscopy. Staining with Imagene Green visualized metabolically active hyphae in all parts of the plant where their presence was expected based on the results described above, and their density in different tissue types was also in accordance with our extract data (Fig. 6). This was most noticeable in cross sections of young plants (Fig. 6a) showing the strong preference of metabolically active hyphae for the leaf sheath of the youngest mature leaf (i.e. the youngest leaf containing a fully differentiated ligule) compared to either older leaf sheaths or immature tissue and emerging leaf. We did not find any hyphae in root tissue among the plants included in this study - one of us has, however, observed such hyphae in other sets of plants (K. Saunders, unpublished observations).

\section{DISCUSSION}

To understand the effect of endophytic fungi on their host grasses we need to identify with far greater precision the interactions between the symbiotic partners. Currently even some very basic questions relating to these interactions remain largely unanswered, such as how the endophyte is actually distributed throughout the plant, and how the overall concentration of endophyte in a plant correlates with the extent of beneficial or detrimental effects. The effects of plant genotype and environmental conditions on the extent and distribution of in planta activity of the endophyte and how plant and endophyte interact in the synthesis of agriculturally important alkaloids formed by the symbiosis are also still largely uncharacterized (Siegel \& Schardl, 1991).

Since methods for the genetic manipulation of grass endophytes have now become available (Schardl \& An, 1993), reporter genes can be used to address these questions. Building on the transformation experiments of Murray et al. (1992) we have therefore devised methods which make the GUS gene a reliable and sensitive tool for studying endophyte-plant interaction. Our methods allow the extraction of endophyteassociated GUS activity with consistent high efficiency from all grass tissues in which the fungus is present. Since background activities are negligible, they thus allow the use of the GUS reporter gene to determine quantitatively the distribution of in planta expression of endophyte genes with unprecedented accuracy and resolution. With the endophytic transformant used in this study, even for low activity tissue such as leaf blade, samples of 1-2 mg dry weight were quite sufficient for GUS activity assays, and for high activity tissues such as leaf sheaths, samples of $10-20 \mu \mathrm{g}$ dry weight would
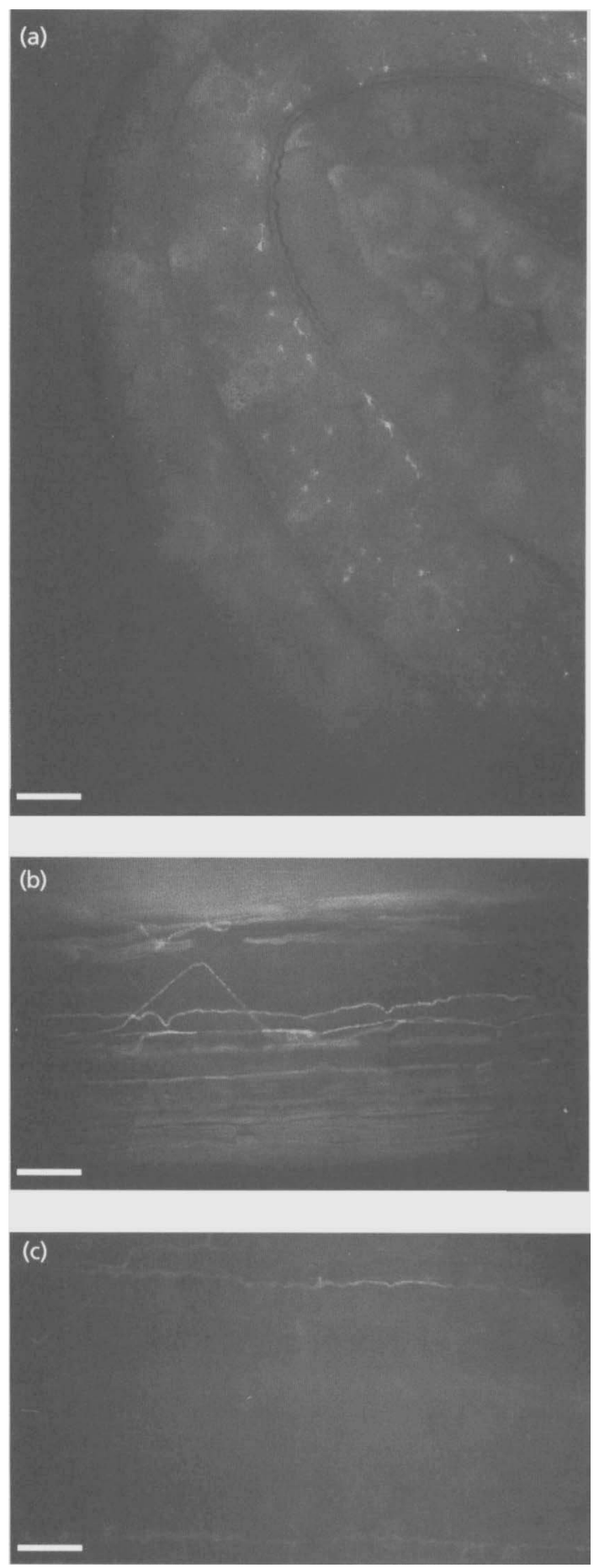

Fig. 6. Visualization of GUS-expressing endophyte hyphae in plant tissue by fluorescence microscopy using Imagene Green. (a) Transverse section through the stem showing a high concentration of fluorescing cross sections of endophyte hyphae in the leaf sheath of the youngest mature leaf; (b) side view of a leaf sheath; (c) side view of a leaf blade. Bars, $100 \mu \mathrm{m}$.

theoretically suffice. Additional information on the spatial distribution of endophyte gene expression can be obtained by use of Imagene dyes which are capable of 
detecting individual GUS-expressing hyphae without the need for fixation or other pretreatments.

In a first application of the method we determined the distribution of endophyte metabolic activity across plants, using constitutive GUS expression as an indicator. Our data on the distribution of endophyte metabolic activity correlate with the few published observations on the in planta distribution of Acremonium mycelium, using antibodies or microscopic assessment of the concentration of hyphae; all of these previous studies describe higher concentrations of hyphae in the lower parts than in the upper parts of grass plants (Ball et al., 1995; Di Menna et al., 1992; Keogh et al., 1996; Musgrave \& Fletcher, 1984) correlating with the gradients of metabolic activity observed in this study. Likewise, Keogh et al. (1996) described differences in the concentration of endophyte between leaves of different age comparable to the differences in metabolic activity observed by us. These sets of data are not directly comparable, having been obtained with different strains of endophytes and grass clones as well as under different growth conditions. Nevertheless the correlation between total endophyte concentration and endophyte metabolic activity suggests that the gradients in endophyte metabolic activity observed by us reflect mainly the distribution of hyphae of similar metabolic activity rather than extreme differences in the metabolic activity between hyphae in different parts of the plant. Furthermore the consistency with which these gradients are observed with different genotypes and under different growth conditions would indicate that they may constitute a general phenomenon applying to many grass-endophyte symbioses.

Due to the sensitivity of our method, our observations provide a more complete and detailed view of these gradients than the studies cited above and thus allow some tentative conclusions as to how spatial patterns of endophyte metabolic activity might be established and maintained throughout proliferation of the plant. Apparently each new leaf becomes infected with endophyte in the earliest stages of emergence in the core of the stem, since endophyte metabolic activity is observed in immature leaf tissue well before it emerges from the stem. A basal-apical gradient of endophyte metabolic activity is established well before the ligule appears as a fully differentiated structure.

Following the differentiation of the ligule, the now mature leaf increases its endophyte metabolic activity both in blade and leaf sheath; however the extent of this increase seems to be highly regulated by two factors. It apparently depends firstly on the overall concentration of endophyte in the plant which, as seen in Fig. 3, does not exceed a certain threshold. Second, the activity increase is restricted so that the overall percentage of endophyte metabolic activity in all leaf sheaths does not exceed $65-85 \%$ and the activity in all blades does not exceed $10-30 \%$; the latter conclusion is based on the observation that these percentages are remarkably constant irrespective of the size of the plant (Fig. 5), whereas concentration of metabolic activity in individual leaves and leaf sheaths varies considerably with plant size (Fig. 4). These restricting mechanisms apparently work simultaneously on all leaves; as the lower activity in older leaves (leaves 3 and 4, Fig. 4) shows, the concentration of metabolic activity of established mature leaves declines as new leaves mature and increase in activity.

Each individual leaf thus seems to go through a cycle in which endophyte metabolic activity first increases as the leaf develops, reaches its peak upon maturation of the leaf (i.e. upon full differentiation of the ligule) and then declines as new leaves are formed at the core of the stem, with the extent of both initial increase and subsequent decline dependent on the concentration of endophyte in other parts of the plant. It would be of importance to determine how endophyte metabolic activity is monitored and controlled by the system; based on some preliminary observations, it seems that the plant plays a considerable and active role in this. Firstly we found that if the same endophyte transformant is introduced into different clones of the same ryegrass cultivar, total endophyte concentration within the different clones can differ by an order of magnitude; this holds true for both GUS activity in extracts as well as the concentration of GUS-expressing hyphae (D. B. Scott, K. Saunders, J. Schmid \& S. Herd, unpublished observations). Secondly in the wilted tips of blades, endophyte metabolic activity increased rather than decreased, suggesting that the decline in endophyte activity in older leaves is not merely a result of the onset of decay.

Many of the apparent 'rules' of endophyte metabolic activity distribution described above may not apply to all endophyte-plant associations but may be specific to the one used in this study. In the future we will therefore extend our observations to test whether the distribution in other endophyte-grass combinations follows similar patterns and how these distributions are affected by environmental conditions such as nutrient or water supply. In some endophyte-grass combinations, the plant appears negatively affected by the endophyte (M. J. Christensen, unpublished observations) and our methods could be used to determine whether this is caused by an excess of endophyte metabolic activity. If we can confirm the differences in the concentration of endophyte metabolic activity between different grass clones of the same species, genomic subtraction methods could be used to identify plant genetic elements responsible for controlling the proliferation of the endophyte. We would also like to combine GUS analysis with assessments of total fungal biomass such as microscopic determination of the volume of endophyte hyphae per dry weight of plant tissue. This would make it possible to determine if the plant only controls endophyte metabolic activity by restricting the amount of mycelium or whether mycelium in different parts of the plant differs in its metabolic activity.

Based on our observation that a similar pattern of endophyte metabolic activity exists in multiple plants of the same genetic background, it will now also be possible 
to complement our assay with others which, since less sensitive, require pooling of material from several plants, such as HPLC analysis of toxins and alkaloids formed by the symbiosis. It should thus be possible to determine if the distribution of these compounds simply follows the same pattern as that of endophyte metabolic activity or whether toxin synthesis pathways are under the control of specific regulatory mechanisms.

Another basic question which can now be addressed is the extent to which the endophyte relies on the host for its supply of basic metabolic precursors. Since housekeeping genes from Acremonium endophytes can be cloned (Collett et al., 1995), it will be possible to judge - using reporter genes - whether they are expressed in planta. If not, the respective endophyte pathway is presumably turned off since its products are provided by the plant.

Quantitative methods for determining endophyte GUS expression in planta should thus rapidly advance our understanding of a variety of aspects of these interesting and important symbioses.

\section{ACKNOWLEDGEMENTS}

We thank Syd Easton, Geoff Lane, Mike Collett and Paul O'Toole for helpful comments on the manuscript. Photography was carried out by Tony Watts. This work was supported by FoRST grant MAU 403 to D. B. S. and J. S. and by grants to J.S. from the New Zealand Lottery Grants Board and the New Zealand Vice Chancellors' Committee.

\section{REFERENCES}

Ball, O. J.-P., Prestidge, R. A. \& Sprosen, J. M. (1995). Interrelationships between Acremonium lolii, peramine and lolitrem B in perennial ryegrass. Appl Env Microbiol 61, 1527-1533.

Bunkers, G. J. (1991). Expression of the Escherichia coli $\beta$ glucuronidase gene in Pseudocercosporella herpotrichoides. Appl Env Microbiol 57, 2896-2900.

Collett, M. A., Bradshaw, R. E. \& Scott, D. B. (1995). A mutualistic fungal symbiont of perennial ryegrass contains two different pyr4 genes, both expressing orotidine- 5 '-monophosphate decarboxylase. Gene 158, 31-39.

Couteaudier, Y., Daboussi, M.-J., Eparvier, A., Langin, T. \& Orcival, J. (1993). The GUS gene fusion system (Escherichia coli $\beta$ D-glucuronidase gene), a useful tool in studies of root colonization by Fusarium oxysporum. Appl Env Microbiol 59, 1767-1773.

Devchand, M. \& Gwynne, D. I. (1991). Expression of heterologous proteins in Aspergillus. J Biotechnol 17, 3-10.

Di Menna, M. E., Mortimer, P. H., Prestidge, R. A., Hawkes, A. D. \& Sprosen, J. M. (1992). Lolitrem B concentrations, counts of Acremonium lolii hyphae, and the incidence of ryegrass staggers in lambs on plots of $A$. lolii-infected perennial ryegrass. $N Z J$ Agric Res 35, 211-217.

Haughland, R. P. (1992). Molecular Probes. Handbook of Fluorescent Probes and Research Chemicals. Eugene, OR : Molecular Probes, Inc.

Jefferson, R. A. (1987). Assaying chimeric genes in plants: the GUS gene fusion system. Plant Mol Biol Rep 5, 387-405.
Keogh, R. G., Tapper, B. A. \& Fletcher, R. H. (1996). Distributions of the fungal endophyte Acremonium lolii, and of the alkaloids lolitrem B and peramine, within perennial ryegrass. N Z J Agric Res 39 121-127.

Latch, G. C. M. \& Christensen, M. J. (1985). Artificial infection of grasses with endophytes. Ann Appl Biol 107, 17-24.

Monke, E. \& Schafer, W. (1993). Transient and stable gene expression in the fungal maize pathogen Cochliobolus beterostrophus after transformation with the $\beta$-glucuronidase (GUS) gene. Mol Gen Genet 241, 73-80.

Murray, F. R., Latch, G. C. M. \& Scott, D. B. (1992). Surrogate transformation of perennial ryegrass, Lolium perenne, using genetically modified Acremonium endophyte. Mol Gen Genet 233, 1-9.

Musgrave, D. R. \& Fletcher, L. R. (1984). The development and application of ELISA detection of Lolium endophyte in ryegrass staggers research. Proc N Z Soc Anim Prod 44, 185-187.

Porter, J. K. (1994). Chemical constituents of grass endophytes. In Biotechnology of Endophytic Fungi of Grasses, pp. 103-123. Edited by C. W. Bacon \& J. F. White, Jr. London: CRC Press.

Punt, P. J., Oliver, R. P., Dingemanse, M. A., Pouwels, P. H. \& van den Hondel, C. A. M. J. J. (1987). Transformation of Aspergillus based on the hygromycin B resistance marker from Escherichia coli. Gene 56, 117-124.

Ride, J. P. \& Drysdale, R. B. (1972). A rapid method for the chemical estimation of filamentous fungi in plant tissue. Pbysiol Plant Pathol 2, 7-15.

Roberts, C. A., Barton, F. E. \& Moore, K. J. (1988). Estimation of Acremonium coenophialum mycelium in infected tall fescue. Agron J 80, 737-740.

Roberts, I. N., Oliver, R. P., Punt, P. J. \& van den Hondel, C. A. M. J.J. (1989). Expression of the Escherichia coli $\beta$ glucuronidase gene in industrial and phytopathogenic filamentous fungi. Curr Genet 15, 177-180.

Schardl, C. L. \& An, Z. (1993). Molecular biology and genetics of protective fungal endophytes of grasses. In Genetic Engineering, pp. 191-212. Edited by J. K. Setlow. New York: Plenum Press.

Scott, B. \& Schardl, C. (1993). Fungal symbionts of grasses: evolutionary insights and agricultural potential. Trends Microbiol 1, 196-200.

Siegel, M. R. \& Schardl, C. L. (1991). Fungal endophytes of grasses: detrimental and beneficial associations. In Microbial Ecology of Leaves, pp. 198-221. Edited by J. H. Andrew \& S. S. Hirano. Berlin: Springer Verlag.

Smit, R. \& Tudzynski, P. (1992). Efficient transformation of Calviceps purpurea using pyrimidine auxotrophic mutants: cloning of the OMP decarboxylase gene. Mol Gen Genet 234, 297-305.

Takenaka, S. (1995). Dynamics of fungal pathogens in host plant tissues. Can J Bot 73, S1275-S1283.

West, C. P. (1994). Physiology and drought tolerance of endophyte-infected grasses. In Biotechnology of Endophytic Fungi of Grasses, pp. 87-99. Edited by C. W. Bacon \& J. F. White, Jr. London: CRC Press.

Received 23 April 1996; revised 9 August 1996; accepted 10 September 1996. 